First Peoples Child \& Family Review

An Interdisciplinary Journal Honouring the Voices, Perspectives, and Knowledges of
First Peoples through Research, Critical Analyses, Stories, Standpoints and Media

Reviews

\title{
Catching Dreams: Applying Gestalt Dream Work to Canadian Aboriginal Peoples
}

\section{Nicole Elliott}

\section{Volume 7, Number 2, 2013}

URI: https://id.erudit.org/iderudit/1068839ar

DOI: https://doi.org/10.7202/1068839ar

See table of contents

Publisher(s)

First Nations Child and Family Caring Society of Canada

ISSN

1708-489X (print)

2293-6610 (digital)

Explore this journal

Cite this article

Elliott, N. (2013). Catching Dreams: Applying Gestalt Dream Work to Canadian Aboriginal Peoples. First Peoples Child \& Family Review, 7(2), 34-42.

https://doi.org/10.7202/1068839ar

\section{Article abstract}

Gestalt therapy is similar to an Aboriginal worldview in that they both involve a holistic approach and focus on health and wellness strategies. The Aboriginal worldview is best portrayed as holistic in nature, where the circle of wellness symbolizes unity, wholeness, completeness, and balance. Dream work is a therapeutic technique utilized in Gestalt therapy that could be very useful for Aboriginal peoples given their spiritual and narrative way of being. This article demonstrates the cultural acceptability for utilization of dream work in Gestalt with Aboriginal clients. Furthermore, it discusses both strengths and limitations of this modality of therapy. Implications for use are also discussed.
This document is protected by copyright law. Use of the services of Erudit (including reproduction) is subject to its terms and conditions, which can be viewed online.

https://apropos.erudit.org/en/users/policy-on-use/ 


\title{
First Peoples Child \& Family Review
}

An Interdisciplinary Journal Honoring the Voices, Perspectives and Knowledges of First Peoples through Research, Critical Analyses, Stories, Standpoints and Media Reviews

\section{Catching Dreams: Applying Gestalt Dream Work to Canadian Aboriginal Peoples}

\author{
Nicole Elliott \\ B.A. (Honours in Psychology), Carleton University (Ottawa, Ontario). \\ Currently an M.A. Candidate in the Counselling Psychology program at the University of Toronto, \\ in the research domain of Aboriginal Mental Health and Healing
}

\begin{abstract}
Gestalt therapy is similar to an Aboriginal worldview in that they both involve a holistic approach and focus on health and wellness strategies. The Aboriginal worldview is best portrayed as holistic in nature, where the circle of wellness symbolizes unity, wholeness, completeness, and balance. Dream work is a therapeutic technique utilized in Gestalt therapy that could be very useful for Aboriginal peoples given their spiritual and narrative way of being. This article demonstrates the cultural acceptability for utilization of dream work in Gestalt with Aboriginal clients. Furthermore, it discusses both strengths and limitations of this modality of therapy. Implications for use are also discussed.
\end{abstract}

\section{Introduction $^{1}$}

I have become acquainted with Aboriginal psychology through my graduate work at the University of Toronto, and possess a deep respect and interest in providing appropriate care and referencing literature that can further benefit the community. Through my involvement in Aboriginal research, I have become engrained in the Aboriginal community of Toronto, through various projects and events. My interest in Aboriginal issues sparked through research involvement with the Canadian Federal Correction system, and from there, my research interests have expanded to cultural identity, spirituality, employment issues, and culturally appropriate counselling techniques for use with Aboriginal peoples. This paper is important to me, as I am currently an aspiring therapist and researcher in the Aboriginal community. The framework and methodology discussed can encourage culturally acceptable resources for therapists working with Aboriginal clients.

Corresponding author:

Nicole Elliott, Ontario Institute for Studies in Education, University of Toronto, 252 Bloor Street St. W., Toronto, ON, Canada, M5S 1V6

\section{Overview of Gestalt Therapy}

Gestalt Therapy, founded in the 1940's by Fritz Perls, is an existential-phenomenological approach to psychotherapy that teaches the importance

1 As a non-Aboriginal person learning and immersing myself in the area of Aboriginal psychology, it is imperative that I acknowledge that this is my own view and that I write from my own position as a student and aspiring mental health professional. What I write does not represent the voice of indigenous people, and speaks only to my own thoughts and interpretations of the literature in relation to this subject. 
of self-awareness through feeling, perceiving and being actively present in the environment, by reorganization of former attitudes and through the creation of new ones. Gestalt therapy is different from many other orientations of psychotherapy in that the primary focus is the client's ability to self regulate in response to their current environment. In essence, Gestalt therapists thrive on the assumption that change will happen naturally throughout the therapeutic process. Gestalt therapy focuses on the present and works with the situation that the client is experiencing in the "here and now" of therapy (Corey, 2009).

A gestalt is a complete experience that is always formed in a relationship with the environment. People form and move from one gestalt to another based on past experiences, current expectations, influences exerted by the situation, and by cultural identity (Mann, 2011). As situations change, so do the corresponding experiences. In Gestalt, this change is referred to as a creative adjustment that signifies the active movement, when an individual recreates a sense of being in reaction to the changing situation. People experience psychological difficulties when the reactions to the environment that have served as useful in the past, do not fit with the current situation. These past reactions may have formed out of habit in response to a perceived lack of support and choice (Mann, 2011).

Gestalt therapy is a holistic body-centered model of psychotherapy, meaning the whole is different and greater than the sum of its parts and is considered the unity of humans with their environment. It does not acknowledge psychological events as being separate from the individual and their situation (Perls, Hefferline \& Goodman, 1994). Holism views the world as an interrelated entity and the ways that we respond to our world are identified as creative synthesis. The philosophy of holism relates well to gestalt theory as both see humans as essential units that are in a constant state of fluctuation and are always evolving (Mann, 2011).

In the dominant Western culture, particularly in North America and Europe there is a heavy emphasis on perceiving the world through an individualistic lens, where people view themselves as separate to those surrounding them. However, experiences cannot be felt or formed as separate from culture. In terms of the field perspective of gestalt, individuals cannot view themselves as being fully independent from those around them, when their inherited assumptions, values, morals, and beliefs regarding the world are grounded by the collected values of the culture as a whole. Therefore, when engaging in therapy through a gestalt lens, it is essential to consider the full range of possible influences that could be potentially affecting the individual, rather than focusing specifically on the problem (Mann, 2011).

The contact boundary is where interaction and withdraw from the environment occurs, and by this process people can creatively adjust in relation to the situation and distinguish the self from others (Perls, Hefferline \& Goodman, 1994). Gestalt theory specifies, that in order for healthy functioning to occur, contact boundaries need to be flexible enough to allow intimacy and autonomy, but must be resistant to things in the environment that are considered to be potentially harmful (Mann, 2011). Perls (1947) noted different ways of diminishing or adjusting contact with the environment that occurs at the contact boundary. As humans, we develop creative adjustments that form in relation to our changing situations. These creative adjustments are, desensitization (numbing the self in an acute phase of a grief reaction); deflection (sidestepping away from direct contact, using generalizing language accompanied by bodily reactions to avoid contact); egotism (observing oneself in relation to the environment, such as in constructive criticism); introjections (developing an attitude, trait or way of being from the environment and internalizing a rulebook that must be followed); retroflection (protection from the environment 


\section{Catching Dreams: Applying Gestalt Dream Work to Canadian Aboriginal Peoples}

by avoidance and internalization of impulses and experiences rather than expression); projection (seeing in others what is present in the self) and confluence (merging or dissolving the contact boundary that results in a lack of differentiation from others) (Mann, 2011; Perls, Hefferline \& Goodman, 1994).

It is important to view these creative adjustments as skills that have been developed and are adjustable and dependant on the situation. Furthermore, some of these processes are more applicable to individualistic cultures rather than from the view of a collectivist culture and must be incorporated with caution during therapy (Mann, 2011). Contact and resistance need to be viewed as part of the same continuum that can be supported depending on the situation. Resistance can be viewed as a means of self-support and must always be viewed in the context of the individual's unique situation (Zinker, 1977).

Gestalt theory also emphasizes the idea that people have a natural tendency and need to create meaningful wholes from their experiences. There are many unfinished situations in life, ranging from those that are trivial to major life events. However, it may not be as essential to complete some tasks as it is for others. If an individual fails to find resolution in these meaningful events, preoccupation with unresolved situations may occur through the expression of psychological distress. A major role of a Gestalt therapist is to facilitate methods to find closure in the "unfinished business" (Mann, 2011). Gestalt therapy is unique to psychotherapeutic approaches because the therapist becomes involved in the client's present situation and therapy is viewed as process, rather than goal oriented. The intended outcome of therapy is to increase an individual's self-awareness and their ability to self-regulate in response to changing perceptions of the environment (Mann, 2011).

\section{Dream work in Gestalt Therapy}

When a person dreams, the hardest aspect to accept is that every part of the dream comes from the individual. Images in a dream are not exactly what they are in reality but are impressions traced by memory combined with attributes, opinions, and attitudes coming from the dreamer. In gestalt therapy, dreams are viewed as being an existential message and a means of creative expression (Fantz \& Roberts, 1998). Each dream is an idiom of an infinite number of associations, conflicts, and contradictions that make up an individual. Dreams express gestalts, usually many at one time. The unfinished part of a gestalt appears in a dream as a split (change in dream content), tension or conflict (Downing \& Marmorstein, 1973).

The existential message in gestalt dream work is to present the dreamer with the disconnected parts of his or her personality. The dream embodies aspects of the person's life and personality that have been rejected from his or her self-concept. The individual can be unaware of aspects of the self that are experienced in the dreams as external to the person (Alban \& Groman, 1975). The dream is a message to the person of how they exist in the world, or the nature of their existence (Harman, 1989). These occur in dreams as avoidances, or as objects or people whom it is impossible or fear provoking to identify. The dream work brings attention to unmet needs that have not been recognized by the dreamer. When a need fulfillment pattern is interrupted, we have recurrent dreams, which will clutter up the person's sleeping field until they are confronted (Fantz \& Roberts, 1998). From a gestalt perspective, the most meaningful types of dreams are recurring dreams because the avoidances of the dreamer are stabilized into a recurring story or variation on a particular theme. The repetition of the dream may also represent a persistent attempt to come to grips with life problems. The repetition makes sense in that it signifies that a gestalt has not been closed (Alban \& Groman, 1975). 
First Peoples Child \& Family Review, Volume 7, Number 2, 2013

Gestalt therapy does not focus on the meaning or symbolism of dreams, but concentrates on the person's experience of that dream. The experience becomes discovery that is deeper and more complete than understanding because it is not limited to the level of intellectualization, thus anyone is capable of finding meaning in his or her dreams (Downing \& Marmorstein, 1973). The gestalt dream therapy approach is integrative. The goal is to go as deep into the actual experience of the dream as possible and from this exploration of experience comes discovery, learning, growth and maturation (Downing \& Marmorstein, 1973). The dreamer must discover the meaning of the dream; therefore the gestalt therapist merely facilitates the process and aids in heightening awareness of the unique meanings of the dream images, and does not interpret the dream (Mann, 2010). This is crucial to dream work in gestalt, because the dreamer is viewed as having better access into the meaning of the dream than the therapist who, can understand and facilitate the dream work, but cannot experience the dream to the same extent as the dreamer (Alban \& Groman, 1975).

Gestalt therapists view dreams as being projections, and thus a way for the individual to resist contact with the environment. These can be either pathological in nature where the impulse is disowned and consequently projected onto the environment; or mindful, creative projections which put the individual's recognized and identified facets against his/her repudiated ones in a confrontation which can lead to discovery and knowledge. Individuals who are very fragmented will have dreams that are more nightmarish in quality, will be filled with holes, avoidances and sterility. Individuals who are well integrated will have dreams with fewer holes, clearer identification, and a more generative process (Fantz \& Roberts, 1998).

The activities that occur during dream work involve real actions, feelings and reactions to the fantasy of the dream occurring in the present moment (Alban \& Groman, 1975). First, the dreamer is asked to explain the dream using first person language as if the dream is occurring in the present. This use of language immerses the dreamer into his or her own experience with greater force than telling the therapist about the dream (Polster \& Polster, 1973). Another method is to ask the dreamer to be the various parts of the dream, which encourages the person's reidentification process. In this experiment the person is helped to play out parts of the dream as if they are aspects of his or her own existence. The individual then works through the dream as a presently occurring event rather than a historical action in order to actively interpret what the dream represents (Polster \& Polster, 1973).

The therapist could also ask the individual to develop a dialogue between the various parts of the dream (Harman, 1989). In this method, the dreamer sits in a chair as Perls titled "the hot seat." Opposite, is an empty chair, which is used to facilitate role-playing of all objects that were involved in the dream. Verbal contact is made with these fantasy objects and a dialogue is produced in which the dreamer speaks for each of the objects. The dreamer addresses the empty chair as if a component part of the dream (disowned aspect of the personality) is seated in the opposite chair (Alban \& Groman, 1975).

\section{Gestalt as a Culturally Appropriate Therapy for Canadian Aboriginal People}

In 2006, approximately one million Canadians reported Aboriginal ancestry, representing 3.8\% of the total Canadian population (Statistics Canada, 2008). It has been argued that the groups' shared experiences of colonization, and the resultant poverty and social stressors have contributed to poorer outcomes across the life span (Frideres \& Gadacz, 2001; Meadows, Lagendyk, Thurston 
\& Eisener, 2003; Mussell, 2005). Furthermore, the spiritual and philosophical foundations that connect Aboriginal people $e^{2}$ from many different nations to the land, creator, and to each other are all quite similar, although there are many diverse groups of Aboriginal peoples in Canada who have heterogeneous cultural aspects. According to Aboriginal tradition in a general sense, life is a path on which the traveler is invited by the Creator and develops in all areas of life so that one can identify and become aware and respectful of his or her surrounding and inner-self along the way while each individual is portrayed as contributing to the collective well being of the group (Loiselle \& Lauretta, 2006; Hamilton \& Sinclair, 1991; Poonwassie \& Charter, 2001; Kirmayer, Simpson \& Cargo, 2001).

Gestalt therapy is similar with Aboriginal worldviews in that they involve a holistic approach and focus on health and wellness strategies. Aboriginal worldviews are best portrayed as holistic in nature, where the circle of wellness symbolizes unity, wholeness, completeness, and balance. The nature of the circle explains that all elements are related to one other. The notion of wholeness and interconnectedness is a fundamental concept of balance and implies the requirement of a balanced attribution of energy, attention, and care between all components of the physical, mental, emotional, and spiritual human being (Loiselle \& Lauretta, 2006; Poonwassie \& Charter, 2001). The Aboriginal way of life is also similar to "self in relation" ideas presented in gestalt theory, where an individual's wellbeing is identified as the relationship to the environment; for example, a traditional teaching states that the fish, the lake and its entire surrounding, must be all treated equally in order for wellbeing to be restored and sustained (Loiselle \& Lauretta, 2006).

\section{Gestalt Dream Work with an Aboriginal population}

The spiritual relationship for Native people is their connection to the earth, the spirit forces, and how they feel cared for and loved by the Creator. This spiritual connection is practiced through ceremonies and daily praying and gratitude. Furthermore, the responsibility to carry on these ceremonies and teaching the spiritual relationships rests with each generation (Hill, 2009). Therefore it is important for Aboriginal people to become or perhaps reconnect with their spiritual self to restore a healthy balance in life, and to pass along this knowledge and teachings to the younger generation to sustain cultural survival. Strengthening cultural identity has also been shown to improve the mental health of Aboriginal people (Martin Hill, 2009).

Spirituality is a component of Indigenous knowledge that includes revelations as understood through dreams, visions or even divine messages (Martin Hill, 2009). Indigenous people view dreaming as a time when the dreamer symbolically processes, synthesizes and resolves the information, questions and experiences that occur each day, with understanding coming from acquired knowledge. Some dreams, which may be called visions or gifts, are especially helpful in answering questions, guiding actions, or making sense of the world (Marsden, 2004). Dreams can be inspired by intent or the need to learn something, whether through prayer or through specific thoughts. In turn, dreams can provide visual answers or models for what the dreamer is trying to understand (Marsden, 2004).

Furthermore, visual representations of dreams can be used to communicate complex ideas, build relationships and restore ancient ways of knowing (Marsden, 2004). Although there are many diverse Aboriginal groups in Canada, many share a commonality in a connection to the earth and the spirits. Many groups share the belief that through dreaming, an individual can

2 Aboriginal is defined by the Canadian Constitution acts (1967-1982) as the people who are Native to Canada, and includes the Indian (First Nations), Inuit and Métis people (Government of Canada, 2013). 
First Peoples Child \& Family Review, Volume 7, Number 2, 2013

have a connection to the spirit world (Tedlock, 2004). Dreams can carry powerful messages from the Creator or teachings from spirits or ancestors (Hill, 2009). Some Indigenous groups also view that dreams occur as a way to convey messages and connect with the animal spirits during hunting, or other spirits in sickness (Kaniuekutat, 2009).

The dream is viewed as a living entity and therefore requires that the dreamer display appropriate etiquette and manners. This has been adapted in therapy to encompass cultural appropriateness for Aboriginal people, clients are taught that when they have a dream, they should acknowledge it with a gift. The gift offered to the dream could be tobacco, food, water, cornmeal, or some offering that they deem appropriate (Duran, 2006). Furthermore, it is appropriate to incorporate dream work into therapy with Aboriginal peoples since dreams are very important to traditional Native beliefs and represents a strong aspect of spirituality. The goal of this type of therapy in regards to an Aboriginal client would be able to attempt a relationship with dreams, at any level of involvement or acculturation with traditional beliefs. The unconscious material in dreams is also the best guide as to where the treatment needs to progress (Duran, 2006). This is especially true for Native individuals who are processing and identifying disowned aspects of the self that have occurred through sexual trauma or through the legacy of historical trauma.

Among many Indigenous groups, dreams are still considered relevant and important for day-to-day life; there is an internally consistent perspective, which validates dreaming. In other groups, such as in Western culture, dreams are often marginalized as fanciful distractions from the real world. If dreaming is significant in Indigenous cultures, practitioners must acknowledge the therapeutic value of dreams when working with Aboriginal clients, as culturally sensitive practices lead to equitable and just societies (Marsden, 2004). Utilizing dream work in therapy with an Aboriginal population may also help in regards to decolonization by re-integrating aspects of traditional culture into dominant cultural therapeutic methods.

Gestalt therapy is a respectable and appropriate approach for psychotherapy with Aboriginal people because it views the individual's problems in relation to their entire environment, including effects of poverty, poor health, colonization, and intergenerational trauma that the group has suffered from as a whole. Gestalt is also spiritual in nature, and can flexibly intertwine aspects of Aboriginal tradition into therapy, such as in dream work and the narrative strategies that it encompasses.

\section{Strengths and areas for development for gestalt dream work with Aboriginal peoples}

Dream work in gestalt therapy has many aspects that can be considered as being parallel to cultural practices for some Aboriginal groups, and when appropriate, can be a valid method for exploring issues with Aboriginal people especially in regards to their spiritual self. However, like many aspects of psychotherapy that have been developed through western thought, dream therapy with Aboriginal people needs to be adjusted to include specific aspects of the Aboriginal worldview. Duran (2006) explains that incorporating two or more ways of knowing can be a harmonious process where the inclusion of two worldviews can integrate the strengths of both approaches. This idea of epistemological hybridism takes the actual life-world of the person or group as the core truth that needs to be seen as valid. In this case, epistemological hybridism exists by utilizing the self-awareness components of gestalt therapy and incorporates them into an Indigenous contextual lens. 
Furthermore, the gestalt therapist who is utilizing dream work with Aboriginal clients must be knowledgeable in Aboriginal tradition in order to be respectful and understand the spiritual nature of dreaming and how it is experienced for that person. For example, an Aboriginal person may view a dream as being a message from the creator or from their ancestors. The therapist must be open to this belief in order to help the Aboriginal client to explore the content and meaning of this dream, while approaching it with the utmost respect. Furthermore, the therapist must be aware of the issues specific to Aboriginal groups such as colonialism and intergenerational trauma, while being attentive to how these issues may arise in dreams whether they are known to the dreamer or not. This is essential for assuring cultural safety within the therapeutic environment. Stewart (2007) emphasizes how it is important to incorporate indigenous approaches to helping and healing when addressing the mental health crisis in Aboriginal communities and populations.

Dream work in gestalt therapy has many aspects that are similar to some of the Aboriginal beliefs regarding spirituality and dreaming, and in some circumstances can be useful in therapy when working with Aboriginal peoples because of its method of delivery. As previously described, during dream therapy the person has full control of where the therapy goes, and is the one who makes meaning out of symbols and activities contoured in the dream. Furthermore, during the dream work session, the client is asked to retell the dream in a story as if it were occurring in the present moment. These techniques are acceptable when working with this specific population, because, not only are individual lived experiences honoured but also Indigenous people usually describe themselves as having an oral-based story telling tradition (Medicine- Eagle, 1980). Therefore, narrative methods in therapy (i.e. client explains dreams or problems by telling their story) are consistent with Aboriginal oral traditions and story telling as ways of knowing and communicating (Stewart, 2008). However, given the widespread violence, abuse, and trauma that is common amongst individuals in some Aboriginal communities, these exercises that incorporate powerful messages through narratives, metaphors, dreams, and fantasies, should be approached in a respectful way, where the individual experiencing the dream must feel that they have entire control over the situation to avoid the risk of re-traumatization.

Another aspect of gestalt dream work therapy, that is appropriate and sensitive for Aboriginal people receiving psychotherapy is dream re-enactment group work. This technique utilizes the entire group, where group members take on the role of various objects or people in the dream. The dreamer then engages in dialogue surrounding each aspect of the dream, as played out by the group members. This could be particularly beneficial for use with an Aboriginal population since many experience issues with colonization and trauma. The group environment would be a safe place for the dreamer to discuss and explore these shared struggles while learning from other members of the group.

Apart from the benefits of using gestalt therapy for Aboriginal people, there are some limitations that must be addressed. First, no two Aboriginal communities are entirely the same. There are more than six hundred different Aboriginal bands residing on over 2,000 reserves across Canada, each having different legal, social, cultural and historical experiences (Voyageur \& Calliou, 2001). Gestalt therapy as a general approach must be individually tailored to meet the needs of each client, considering their particular history and traditions. When using dream work in gestalt therapy with Aboriginal people, the therapist must also respect the diversity of Aboriginal groups, and have a thorough understanding of the meaning and importance of dreaming in the tradition of the Aboriginal individual whom the therapist is helping. For example, Some Innu communities view recurring dreams as bad omens and an individual who talks about the recurring dream is thought to bring back luck to the community (Kaniuekutat, 2009). This is an 
First Peoples Child \& Family Review, Volume 7, Number 2, 2013

important issue to address since recurring dreams in gestalt therapy are viewed as being the most important for learning and exploring the aspects of the self. Furthermore, gestalt therapy should not be the main or only means of healing for Aboriginal people. Guidance from a traditional healer or elder in the community should be the primary aspect of the healing journey. When an individual is already receiving services from a traditional elder or healer, gestalt therapy could be actively incorporated into the healing process.

Second, the gestalt therapist must be aware of the creative adjustment processes that are viewed negatively in Western culture, since gestalt theory was proposed based on individualistic views. The concepts of confluence and introjections are viewed as being maladaptive through the individualistic lens. However, they are considered to represent growth and healthy adaptations to someone with a collectivist worldview (Mann, 2011). This further emphasizes the value that is placed on the therapists involvement in the here and now, and their grounding and understanding of the historical background in relevance to the individual's current situation.

Gestalt therapy is a creative approach to psychology that embraces a holistic model to value each aspect of an individual's experiences in order to create self-awareness in the present moment. Furthermore, because of its humanistic methods, narrative styles, and commonalities to Aboriginal world-views and traditions, dream work in gestalt therapy can be utilized as a powerful tool to help Canadian Aboriginal people along their healing journey.

\section{References}

Alban, L.S. \& Groman, W.D. (1975). Dream work in a gestalt therapy context. TheAmerican Journal of Psychoanalysis, 35, 147-156.

Corey, G. (2009). Gestalt Therapy. Theory and Practice of Counseling and Psychotherapy (8th ed.). Brooks/Cole, Belmont: CA. 197-231.

Downing, J. \& Marmorstein, R. (1973). Dreams and nightmares: A book of gestalt therapy dream work sessions. The Gestalt Journal Press, Gouldsboro: ME.

Duran, E. (2006). Healing the soul wound: Counseling with American Indians and other Native peoples. Teachers College Press, New York: NY.

Fantz, R.E. \& Roberts, A. (1998). The dreamer and the dream: Essays and reflections on gestalt therapy. The Gestalt Institute of Cleveland Press, Cleveland: $\mathrm{OH}$.

Frideres, J.S., \& Gadacz, R.R. (2001). Aboriginal Peoples in Canada: Contemporary Conflicts (6th ed.). Toronto, ON: Pearson Education Canada Inc.

Government of Canada (2013). Rights of the Aboriginal Peoples of Canada. Constitution Acts, 1867 to 1982 . Retrieved March 5, 2013 from: http://laws-lois.justice.gc.ca/eng/Const/page-16.html

Hamilton, A.C., \& Sinclair, C.M. (1991). Aboriginal concepts of justice. Vol. 1. Report of the Aboriginal justice inquiry of Manitoba: The justice system and Aboriginal people (pp. 17-46). Winnipeg, Canada: Queen's Printer.

Harman, R.L. (1989). Gestalt Therapy with groups, couples, sexually dysfunctional men, and dreams. Charles C Thomas, Springfield: IL.

Hill, W. (2009). Understanding life: What my ancestors taught me through my dreams. Red Lead Press, Pittsburgh: PA.

Kaniuekutat (2009). I dreamed the animals: A hunter's journal. Cultural Survival: Native Women's Hidden Reality, 33 (3).

Kirmayer, L., Simpson, C., \& Cargo, M. (2003). Healing traditions: Culture, community and mental health promotion with Canadian Aboriginal peoples. Australasian Psychiatry, 11, 15-23. 


\section{Catching Dreams: Applying Gestalt Dream Work to Canadian Aboriginal Peoples}

Loiselle, M. \& Lauretta, M. (2006). The wellness wheel: An Aboriginal contribution to social work. First North-American Conference on Spirituality and Social Work. Waterloo, ON.

Mann, D. (2011). Gestalt therapy: 100 Key Points \& Techniques. Routledge, New York: NY.

Marsden, D. (2004). Expanding knowledge through dreaming, wampum and visual arts. Pimatisiwin: A Journal of Aboriginal and Indigenous Community Health, 2, 53-73.

Martin Hill, D.M. (2009). Traditional medicine and restoration of wellness strategies. Journal of Aboriginal Health, 26-42.

Meadows, L.M., Lagendyk, L.E., Thurston, W.E., \& Eisener, A.C. (2003). Balancing culture, ethics and methods in qualitative health research with Aboriginal peoples. International Journal of Qualitative Methods, 2 (4). Article 1.

Medicine-Eagle, B. (1989). The circle of healing. In N.R. Carlson, B. Shields, \& J. Brugh (Eds.), Healers on Healing (pp. 58-62). New York: J.P Tarcher/ Putnam.

Mussell, W.J. (2005). Warrior-caregivers: Understanding the Challenges and Health of First Nations men. A resource Guide. Ottawa, ON: Aboriginal Healing Foundation.

Perls, F.S., Hefferline, R. \& Goodman, P. (1994). Gestalt Therapy: Excitement and growth in the human personality. The Gestalt Journal Press, Gouldsboro: ME.

Polster, E. \& Polster, M. (1973). Gestalt therapy integrated: Contours of theory and practice. Vintage Books, New York: NY.

Poonwassie, A., \& Charter, A. (2001). An Aboriginal worldview of helping: Empowering approaches. Canadian journal of counselling, 35 (1), 63-73.

Statistics Canada (2008). Aboriginal Peoples in Canada in 2006: Inuit, Métis and First Nations, 2006 Census. Ottawa, $\mathrm{ON}$ : Author.

Stewart, S. (2007). Indigenous helping and healing in counselor training. Centre for Native policy and research monitor, 2, 53-65.

Stewart, S. (2008). Promoting Indigenous mental health: Cultural perspectives on healing from Native counselors in Canada. International Journal of Health Promotion and Education, 46, 49-56.

Tedlock, B. (2004). The poetics and spirituality of dreaming: A Native American enactive theory. Dreaming, 14 (2-3), 183-189.

Voyageur, C.J., \& Calliou, B. (2001). Various shades of red: Diversity within Canada's Indigenous community. London Journal of Canadian Studies, 16, 109-123.

Zinker, J. (1977). Creative process in Gestalt therapy. Vintage Books, New York: NY. 